\title{
Rare Earth Elements in the Lignite Ash Determination Method Development
}

\author{
Oleg I. Podkopaev ${ }^{\mathrm{a}}$, Ekaterina S. Balakchina ${ }^{\mathrm{a}}$, \\ Vladimir N. Losev ${ }^{\mathrm{b}}$, Svetlana A. Kopytkova ${ }^{a}$, \\ Vladimir A. Kulagin ${ }^{b}$ and Aleksandr F. Shimanskii*b \\ ${ }^{a} J S C$ «GERMANIUM» \\ 1/107 Transportny proezd, Krasnoyarsk, 660027, Russia \\ ${ }^{b}$ Siberian Federal University \\ 79 Svobodny, Krasnoyarsk, 660041, Russia
}

Received 18.04.2016, received in revised form 29.07.2016, accepted 03.09.2016

The possibility of using the lignite ash from central watershed of the Yenisei river as a new rare earth elements raw material source was shown. Lignite ash rare earth elements inductively coupled plasma atomic emission spectroscopy determination method was developed. It was found that total concentration of rare earth elements in the ash is from 300 to $2500 \mathrm{~g} / \mathrm{t}$.

Keywords: lignite, rare earth elements, atomic emission spectroscopy, determination.

Citation: Podkopaev O.I., Balakchina E.S., Losev V.N., Kopytkova S.A., Kulagin V.A., Shimanskii A.F. Rare earth elements in the lignite ash determination method development, J. Sib. Fed. Univ. Eng. technol., 2016, 9(8), 1238-1246. DOI: 10.17516/1999-494X-2016-9-8-1238-1246.

\section{Разработка методики определения \\ редкоземельных элементов в золе лигнитов}

\author{
О.И. Подкопаев ${ }^{a}$, Е.С. Балакчина ${ }^{a}$ В.Н. Лосев ${ }^{\sigma}$, \\ С.А. Копыткова ${ }^{a}$, В.А. Кулагин ${ }^{\tilde{\sigma}}$, А.Ф. Шиманский ${ }^{\tilde{\sigma}}$

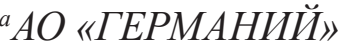 \\ Россия, 660027, Красноярск, Транспортный проезд, 1/107 \\ ${ }^{6}$ Сибирский федеральный университет \\ Россия, 660041, Красноярск, пр. Свободный, 79
}

Показано, что зола лигнитов бассейна среднего течения р. Енисей может рассматриваться как сырьевой источник редкоземельных элементов. Разработана методика атомноэмиссионного с индуктивно связанной плазмой определения редкоземельных элементов в золе

(c) Siberian Federal University. All rights reserved

* Corresponding author E-mail address: shimanaf@mail.ru 
Oleg I. Podkopaev, Ekaterina S. Balakchina... Rare Earth Elements in the Lignite Ash Determination Method Development

лигнита Касского месторождения. Выявлено, что суммарное содержание РЗЭ составляет от 300 до $2500 \mathrm{c} / \mathrm{m}$.

Ключевые слова: лигнит, редкоземельные элементы, атомно-эмиссионная спектроскопия, определение.

Редкоземельные элементы (РЗЭ) используют при производстве высокоэнергетических постоянных магнитов, современных конструкторских материалов, оптики и стекла, люминофоров, в радиоэлектронике, атомной технике, машиностроении, химической и нефтехимической промышленности [1]. Ежегодно увеличивается потребление РЗЭ в автомобилестроении и современных военных технологиях [2].

Как правило, РЗЭ встречаются совместно в минералах и рудах. Почти три четверти РЗЭ ресурсов сконцентрировано в Мурманской области, где главной освоенной частью сырьевой базы России являются Ловозерское месторождение лопарита и апатитовые месторождения Хибинского региона с содержанием РЗЭ около 1 \%. Уникальные томторские руды в Якутии составляют около 16 \% запасов РЗЭ. Высоким содержанием РЗЭ характеризуется Катугинское месторождение в Восточной Сибири и ряд месторождений, расположенных на территории республик Коми, Тыва и Красноярского края [3]. Прогнозные ресурсы РЗЭ России в целом оцениваются как крупные и составляют 5,2 млн т в пересчёте на сумму оксидов [1].

Одним из перспективных направлений расширения сырьевой базы редкоземельных элементов является использование различного вида техногенного сырья - отходов горнометаллургического и топливно-энергетического комплексов. Данные отходов содержат относительно высокие концентрации титана, циркония, иттрия, ванадия, галлия, германия и других ценных металлов, в том числе редкоземельных [4].

Одним из предприятий по получению рассеянного элемента германия является предприятие АО «ГЕРМАНИЙ» (г. Красноярск). Основным видом минерального сырья для получения германия служат угли, в которых также присутствуют редкоземельные элементы. Промышленные запасы германиеносного сырья сосредоточены в бурых углях и углистых породах (apгиллитах, алевролитах) на Сахалине, в Приморском крае и Читинской области.

Один из основных процессов в технологии получения германия основан на сжигании углей и других углеродсодержащих материалов (антрацитов, углистых аргиллитов и алевролитов) с концентрированием германия в возгонах, которые являются первичным концентратом германия. После отгонки германия в газовую фазу в процессе сжигания углеродсодержащего сырья остальные присутствующие в нем металлы концентрируются в золе. Перспективный источник германия - лигниты Красноярского края, месторождения которых расположены в бассейне среднего течения р. Енисей (Нижнее Приангарье).

В золе после сжигания лигнитов в значительном количестве обнаружено присутствие других металлов: ванадия, титана, бериллия, циркония, иттрия, скандия и редкоземельных металлов $[5,6]$. Поэтому зола лигнитов может рассматриваться как сырьевой источник для редкоземельных элементов. Для группового определения редкоземельных элементов необходимо использование многоэлементного метода анализа, обладающего высокой чувствительностью. Данному условию удовлетворяет метод атомно-эмиссионной спектрометрии с индуктивно связанной плазмой. 
В настоящей статье предложена методика атомно-эмиссионного с индуктивно связанной плазмой определения редкоземельных металлов в золах после сжигания лигнитов.

\section{Методы и материалы}

Аппаратура. Концентрацию элементов определяли на атомно-эмиссионном спектрометре с индуктивно связанной плазмой іCAP 6300 Duo (Thermo Scientific, США) с циклонной распылительной камерой типа Tracey, изготовленной из боросиликатного стекла, с концентрическим распылителем OpalMist из фторопласта. Операционные параметры прибора выбраны в соответствии с рекомендациями фирмы-изготовителя: мощность генератора 1150 Вт; плазмообразующий газ 12 л/мин; промежуточный газ 0,5 л/мин; распыляющий газ 0,7 л/мин; распылитель/распыляющая камера OpalMist / циклонная; перистальтический насос 50 об/мин.

При определении концентрации металлов использовали эмиссионные линии, имеющие наибольшую интенсивность и свободные от спектральных наложений.

Озоление проб углей, углистых аргиллитов, лигнитов для удаления органической части проводили в лабораторной муфельной печи SNOL 7,2/1100 (Литва) с рабочим диапазоном температур от 50 до $1100{ }^{\circ} \mathrm{C}$.

Разложение проб золы проводили при атмосферном давлении на нагревательной системе пробоподготовки с контролем температуры Hot Block (Environmental Express, США) в пробирках из полипропилена.

Реагенты. В качестве стандартного раствора редкоземельных элементов (Ce, Dy, Er, Eu, $\mathrm{Gd}, \mathrm{Ho}, \mathrm{La}, \mathrm{Lu}, \mathrm{Nd}, \mathrm{Pr}, \mathrm{Sc}, \mathrm{Sm}, \mathrm{Tb}, \mathrm{Tm}, \mathrm{Y})$ использовали стандартный образец состава растворов редкоземельных элементов (МЭС РЗЭ) фирмы ООО НПП «СКАТ» (г. Новосибирск) с исходной концентрацией элементов 50 мкг/мл и $\mathrm{Yb}-25$ мкг/мл. Рабочие растворы с концентрацией 1 и 5 мкг/мл редкоземельных элементов, 0,5 и 2,5 мг/л Үb готовили разбавлением стандартного раствора деионизованной водой.

В качестве стандартных растворов сопутствующих элементов применяли стандартные образцы состава МЭС-1 (Al, Ca, Cd, Fe, Mg, Mn, Na, Cr, Zn, Li, K, P), MЭC-2 (Ba, V, Bi, Ga, In, $\mathrm{Co}, \mathrm{Cu}, \mathrm{Ni}, \mathrm{Si}, \mathrm{Ti}, \mathrm{Na}$ ), MЭC-3 (As, Sn, Pb, Sb, Te, Ba, Ag, Sr), MЭC-4 (W, Mo, Nb) с концентрацией элементов 50 мкг/мл. Рабочие растворы сопутствующих элементов с концентрацией 10 мг/л готовили разбавлением стандартных растворов деионизованной водой.

10\%-ный раствор борной кислоты готовили растворением точной навески борной кислоты квалификации х.ч. при нагревании в деионизованной воде.

Одноэлементные растворы $\mathrm{Fe}, \mathrm{Ca}, \mathrm{Ti}, \mathrm{Mn}, \mathrm{Cr}$ готовили из стандартных растворов фирмы Inorganic Ventures (США) с концентрацией элемента 1000 мг/л.

Раствор скандия (1000 мг/л), используемого в качестве внутреннего стандарта при определении матричных элементов, готовили растворением точной навески металлического скандия чистоты 99,999 \% в небольшом объеме концентрированной $\mathrm{HNO}_{3}$ при нагревании на водяной бане. После полного растворения навески раствор переносили в мерную колбу на 250 мл и доводили до метки $2 \mathrm{M} \mathrm{HNO}_{3}$.

Раствор кадмия (1000 мг/л), используемого в качестве внутреннего стандарта при определении содержания германия и редкоземельных элементов, готовили растворением точной навески кадмия азотнокислого 4-водного квалификации ч.д.а в 0,1 $\mathrm{M} \mathrm{HNO}_{3}$.

$$
-1240-
$$


В работе применяли концентрированные соляную, азотную и фтористоводородную кислоты квалификации х.ч.

Методика эксперимента. Навеску (2,0000 г) углей, углистых аргиллитов, лигнитов помещали в кварцевые лодочки и озоляли в муфельной печи при медленном подъеме температуры до $350{ }^{\circ} \mathrm{C}$ в течение 2 ч, выдерживали 2 ч, далее поднимали температуру до $550{ }^{\circ} \mathrm{C}$ и выдерживали 2 ч. Зольность пробы определяли по формуле

$$
A_{a}(\%)=\frac{m_{3}-m_{1}}{m_{2}-m_{1}} \cdot 100
$$

где $\mathrm{m}_{1}$ - масса тигля; $\mathrm{m}_{2}$ - масса тигля с пробой; $\mathrm{m}_{3}$ - масса тигля с навеской.

При определении матричных и редкоземельных элементов навеску 0,1000 г золы помещали в полипропиленовую пробирку, добавляли 8 мл концентрированной $\mathrm{HNO}_{3}$ и 2 мл смеси концентрированной $\mathrm{HCl}$ и $\mathrm{HF}$ (7:3). Пробирку закрывали винтовой крышкой, помещали в ячейку в системе пробоподготовки Hot Block, нагревали до $105^{\circ} \mathrm{C}$ и выдерживали в течение 3 ч. Пробирку открывали, добавляли 3 мл 10 \%-ного раствора борной кислоты, закрывали крышкой и продолжали нагрев раствора пробы в течение 1 ч при тех же условиях. Раствор от осадка отделяли фильтрованием через фильтр «синяя лента» в мерную колбу на 50 мл, добавляли 0,5 мл раствора кадмия в качестве внутреннего стандарта и доводили до метки деионизованной водой.

Содержание РЗЭ в золе и в исходном образце рассчитывали по формулам (2) и (3) соответственно, а содержание матричных элементов в золе - по формуле (4):

$$
\begin{aligned}
& Э(2 / m)=\frac{X \cdot 50}{H}, \\
& Э(2 / m)=\frac{X \cdot 50 \cdot A^{a}}{H \cdot\left(100-W_{a}\right)}, \\
& Э(\%)=\frac{X \cdot 50}{H \cdot 10000},
\end{aligned}
$$

где $\mathrm{X}$ - аналитический сигнал, мг/ дм³; 50 - конечный объем пробы, мл; $\mathrm{A}^{\mathrm{a}}$ - зольность пробы, \%; H - навеска пробы, г; $\mathrm{W}_{\mathrm{a}}$ - аналитическая влага пробы, \%.

\section{Результаты и их обсуждение}

Определение матричных элементов в золе лигнитов. Содержание углерода и кислорода в лигните составляют 68 и 27 мас. \% соответственно [7].

Озоление позволяет удалить из пробы углеродную составляющую, что вызывает увеличение содержания элементов в золе. Присутствие матричных элементов в анализируемой пробе может приводить к появлению систематических ошибок, связанных со спектральным наложением, при определении редкоземельных элементов. Определение содержания матричных элементов в золе лигнита (технологическая проба Касского месторождения) показывает, что их содержание немного выше, чем в золе углей и аргиллита (табл. 1).

Как видно из табл. $1 \mathrm{Al}, \mathrm{Ca}, \mathrm{Fe}, \mathrm{Si}, \mathrm{Ti}$ содержатся в золе в преобладающих количествах.

Определение редкоземельных элементов в золе лигнитов. Исследования проб лигнитов Касского месторождения рентгенофлуоресцентным методом показали, что совместно с герма- 
Таблица 1. Содержание матричных элементов в образцах золы (n=5, P=0,95)

\begin{tabular}{|c|c|c|c|c|}
\hline Проба & Лигнит & Бурый уголь & Уголь & Аргиллит \\
\hline Элемент & \multicolumn{4}{|c|}{ Содержание элемента, мас. \% } \\
\hline $\mathrm{Al}$ & $5,09 \pm 0,61$ & $3,23 \pm 0,39$ & $3,25 \pm 0,39$ & $4,02 \pm 0,48$ \\
\hline As & $0,05 \pm 0,006$ & $0,03 \pm 0,005$ & $0,07 \pm 0,008$ & $<0,01$ \\
\hline $\mathrm{Ba}$ & $0,07 \pm 0,008$ & $0,05 \pm 0,006$ & $0,04 \pm 0,005$ & $0,02 \pm 0,002$ \\
\hline $\mathrm{Ca}$ & $3,29 \pm 0,40$ & $0,27 \pm 0,03$ & $0,73 \pm 0,09$ & $0,23 \pm 0,03$ \\
\hline $\mathrm{Co}$ & $0,15 \pm 0,02$ & $0,02 \pm 0,004$ & $0,003 \pm 0,001$ & $<0,001$ \\
\hline $\mathrm{Cr}$ & $0,43 \pm 0,05$ & $0,18 \pm 0,02$ & $0,04 \pm 0,005$ & $0,01 \pm 0,003$ \\
\hline $\mathrm{Cu}$ & $0,07 \pm 0,008$ & $0,02 \pm 0,003$ & $0,003 \pm 0,001$ & $0,007 \pm 0,001$ \\
\hline $\mathrm{Fe}$ & $8,82 \pm 1,06$ & $5,07 \pm 0,60$ & $6,61 \pm 0,79$ & $1,59 \pm 0,19$ \\
\hline $\mathrm{K}$ & $0,75 \pm 0,09$ & $1,48 \pm 0,18$ & $1,73 \pm 0,21$ & $1,69 \pm 0,20$ \\
\hline $\mathrm{Mg}$ & $0,49 \pm 0,06$ & $0,13 \pm 0,02$ & $0,24 \pm 0,03$ & $0,41 \pm 0,05$ \\
\hline Mn & $0,06 \pm 0,007$ & $0,02 \pm 0,002$ & $0,18 \pm 0,02$ & $0,02 \pm 0,002$ \\
\hline $\mathrm{Na}$ & $0,12 \pm 0,01$ & $0,11 \pm 0,01$ & $0,18 \pm 0,02$ & $0,35 \pm 0,04$ \\
\hline $\mathrm{Ni}$ & $0,17 \pm 0,02$ & $0,04 \pm 0,005$ & $0,02 \pm 0,003$ & $0,005 \pm 0,001$ \\
\hline $\mathrm{P}$ & $0,03 \pm 0,004$ & $0,01 \pm 0,003$ & $0,02 \pm 0,004$ & $0,03 \pm 0,004$ \\
\hline $\mathrm{Si}$ & $20,18 \pm 2,42$ & $30,25 \pm 3,03$ & $33,77 \pm 4,05$ & $32,41 \pm 3,87$ \\
\hline $\mathrm{Sr}$ & $0,04 \pm 0,005$ & $0,004 \pm 0,001$ & $0,007 \pm 0,001$ & $0,004 \pm 0,001$ \\
\hline $\mathrm{Ti}$ & $1,49 \pm 0,18$ & $1,40 \pm 0,17$ & $0,42 \pm 0,05$ & $0,48 \pm 0,06$ \\
\hline $\mathrm{Zn}$ & $0,19 \pm 0,02$ & $0,02 \pm 0,002$ & $0,01 \pm 0,003$ & $0,11 \pm 0,02$ \\
\hline
\end{tabular}

нием в лигнитах содержатся рассеянные (церий, лантан, скандий) и некоторые редкоземельные элементы (неодим, иттрий) [8]. Ограниченная чувствительность РФА не позволяет определить содержание других редкоземельных элементов, находящихся в концентрациях ниже предела обнаружения РФА. Однако с учетом зольности лигнитов, составляющей порядка 5 \%, суммарное содержание РЗЭ в золе может превышать 150 г/т.

Проведено определение содержания в золе лигнита всей группы РЗЭ атомноэмиссионным с индуктивно связанной плазмой методом и установление соотношения между их количеством и количеством германия, поскольку лигниты Касского месторождения рассматриваются как перспективный источник германия. Проанализированы пробы зол лигнита с различным содержанием германия в исходном лигните от 20 до 500 г/т с различных участков месторождения.

При определении низких концентраций РЗЭ появляются спектральные наложения линий элементов матрицы ( $\mathrm{Fe}, \mathrm{Mn}, \mathrm{Ti}, \mathrm{Cr}, \mathrm{Ca})$, приводящие к завышенным результатам.

При наличии матричных влияний от двух элементов выбирали наибольшее влияние одного из них. Если спектральное наложение от двух элементов значительно и нельзя выделить один из них, то предпочтительнее выбрать аналитическую линию, свободную от спектральных наложений.

Для определения элементов матрицы, оказывающих спектральное наложение на линии определенного РЗЭ, использовали одноэлементные растворы матричных элементов с концен- 
трацией элемента состава матрицы, близкой к концентрации в анализируемых пробах: раствор иона железа с концентрацией 200 мг/л, раствор кальция - 50 мг/л, раствор титана - 50 мг/л, раствор марганца - 10 мг/л, раствор хрома - 10 мг/л.

После определения матричных элементов, влияющих на линии РЗЭ, дальнейший учет влияния осуществляли с помощью программного обеспечения прибора с учетом коэффициента спектрального наложения (КСН).

По результатам исследований из ряда наиболее интенсивных аналитических линий редкоземельных элементов для их определения выбраны линии, приведенные в табл. 2, в которой представлены матричные элементы, оказывающие максимальное влияние на линии РЗЭ.

Для остальных редкоземельных элементов выбраны аналитические линии, свободные от спектральных наложений матричных элементов: Ce 413.765 нм; Er 349.910 нм; Nd 430.358 нм; Pr 423.293 нм; Ть 365.888 нм; Ү 371.030 нм.

Содержание РЗЭ в золе проб лигнитов с различным содержанием германия приведено в табл. 3.

Как видно из табл. 3, отсутствует зависимость содержания РЗЭ от содержания германия в исходном лигните, а содержание суммы РЗЭ колеблется в достаточно широких пределах - от 300 до 2500 г/т.

В результате сжигания лигнита содержание редкоземельных элементов в золе возрастает примерно в 20 раз (табл. 4) и составляет 0,25 мас. \%, что позволяет рассматривать золу лигнитов как сырье РЗЭ.

Разработанная методика дает возможность определять элементный состав лигнитов и других германийсодержащих сырьевых материалов, а также определять Р3Э с учетом матричных влияний проб.

\section{Заключение}

Методом атомно-эмиссионной спектроскопии с индуктивно-связанной плазмой показано, что суммарное содержание редкоземельных элементов в золе лигнита достигает 0,25 мас. \%, что сопоставимо с содержанием РЗЭ в рудах. Наши данные свидетельствуют о перспектив-

Таблица 2. Эмиссионные линии определяемых и мешающих элементов

\begin{tabular}{|c|c|c|}
\hline Номер п/п & Элемент; длина волны, нм & $\begin{array}{c}\text { Мешающий элемент } \\
\text { для расчета КСН }\end{array}$ \\
\hline 1 & Dy 353,170 & Mn \\
\hline 2 & Eu 381,967 & Fe \\
& Gd 299,904 & \\
& Lu 261,542 & \\
& Pr 511,076 361,384 & \\
\hline 3 & Yb 328,937 & Ti \\
& Ho345,600 & Cr \\
\hline 4 & La 333,749 346,220 & Tm \\
\hline
\end{tabular}


Таблица 3. Содержание редкоземельных элементов в золе проб лигнита с различным содержанием германия $(\mathrm{n}=5, \mathrm{P}=0.95)$

\begin{tabular}{|c|c|c|c|c|c|c|c|c|}
\hline $\begin{array}{r}\text { Наименование } \\
\text { пробы }\end{array}$ & $\begin{array}{c}\text { Проба } \\
\text { № } 1\end{array}$ & $\begin{array}{c}\text { Проба } \\
\text { № } 2\end{array}$ & $\begin{array}{c}\text { Проба } \\
\text { № } 3\end{array}$ & $\begin{array}{l}\text { Проба } \\
\text { № 4* }\end{array}$ & $\begin{array}{c}\text { Проба } \\
\text { № } 5\end{array}$ & $\begin{array}{c}\text { Проба } \\
\text { № } 6\end{array}$ & $\begin{array}{c}\text { Проба } \\
\text { № } 7\end{array}$ & $\begin{array}{c}\text { Проба } \\
\text { № } 8\end{array}$ \\
\hline Элемент & \multicolumn{8}{|c|}{ Содержание Ge, г/т } \\
\hline Р3Э, г/Т & 22 & 90 & 150 & 229 & 305 & 355 & 433 & 486 \\
\hline $\mathrm{Ce}$ & $54 \pm 9$ & $38 \pm 4$ & $30 \pm 13$ & $668 \pm 70$ & $118 \pm 5$ & $44 \pm 5$ & $434 \pm 82$ & $118 \pm 19$ \\
\hline Dy & $9 \pm 4$ & $11 \pm 3$ & $4 \pm 1$ & $104 \pm 20$ & $15 \pm 2$ & $10 \pm 1$ & $112 \pm 26$ & $18 \pm 4$ \\
\hline $\mathrm{Er}$ & $17 \pm 1$ & $20 \pm 4$ & $17 \pm 5$ & $90 \pm 12$ & $31 \pm 2$ & $19 \pm 2$ & $77 \pm 19$ & $30 \pm 4$ \\
\hline $\mathrm{Eu}$ & $<1$ & $<1$ & $<1$ & $28 \pm 5$ & $2 \pm 1$ & $1 \pm 0$ & $23 \pm 5$ & $3 \pm 0$ \\
\hline $\mathrm{Gd}$ & $15 \pm 4$ & $15 \pm 2$ & $4 \pm 1$ & $113 \pm 11$ & $11 \pm 3$ & $3 \pm 1$ & $106 \pm 28$ & $16 \pm 6$ \\
\hline Ho & $1 \pm 0$ & $2 \pm 1$ & $<1$ & $20 \pm 3$ & $4 \pm 1$ & $3 \pm 0$ & $22 \pm 8$ & $3 \pm 0$ \\
\hline $\mathrm{La}$ & $40 \pm 2$ & $30 \pm 2$ & $25 \pm 10$ & $212 \pm 25$ & $48 \pm 14$ & $24 \pm 6$ & $134 \pm 27$ & $55 \pm 13$ \\
\hline $\mathrm{Lu}$ & $4 \pm 1$ & $9 \pm 1$ & $5 \pm 2$ & $10 \pm 2$ & $5 \pm 1$ & $4 \pm 1$ & $8 \pm 3$ & $2 \pm 0$ \\
\hline $\mathrm{Nd}$ & $33 \pm 4$ & $25 \pm 5$ & $19 \pm 5$ & $437 \pm 53$ & $33 \pm 10$ & $13 \pm 4$ & $359 \pm 42$ & $46 \pm 10$ \\
\hline $\operatorname{Pr}$ & $33 \pm 7$ & $26 \pm 5$ & $35 \pm 12$ & $95 \pm 20$ & $13 \pm 4$ & $18 \pm 0$ & $68 \pm 15$ & $23 \pm 8$ \\
\hline $\mathrm{Sc}$ & $32 \pm 1$ & $13 \pm 2$ & $20 \pm 7$ & $152 \pm 20$ & $23 \pm 5$ & $18 \pm 1$ & $86 \pm 14$ & $26 \pm 1$ \\
\hline $\mathrm{Sm}$ & $11 \pm 1$ & $10 \pm 3$ & $10 \pm 2$ & $114 \pm 13$ & $10 \pm 2$ & $9 \pm 1$ & $83 \pm 12$ & $20 \pm 4$ \\
\hline $\mathrm{Tb}$ & $<1$ & $<1$ & $<1$ & $20 \pm 3$ & $<1$ & $<1$ & $21 \pm 7$ & $1 \pm 0$ \\
\hline $\mathrm{Tm}$ & $2 \pm 1$ & $6 \pm 1$ & $3 \pm 1$ & $38 \pm 8$ & $4 \pm 1$ & $4 \pm 0$ & $10 \pm 5$ & $3 \pm 1$ \\
\hline $\mathrm{Y}$ & $133 \pm 8$ & $118 \pm 17$ & $85 \pm 15$ & $276 \pm 40$ & $139 \pm 36$ & $115 \pm 24$ & $169 \pm 32$ & $99 \pm 11$ \\
\hline $\mathrm{Yb}$ & $23 \pm 3$ & $37 \pm 5$ & $25 \pm 10$ & $80 \pm 15$ & $29 \pm 4$ & $26 \pm 1$ & $67 \pm 14$ & $16 \pm 2$ \\
\hline
\end{tabular}

Примечание: *технологическая проба.

Таблица 4. Содержание Р3Э в лигните и золе лигнита технологической пробы $(\mathrm{n}=5, \mathrm{P}=0,95)$

\begin{tabular}{|c|c|c|}
\hline \multirow{2}{*}{ Элемент } & \multicolumn{2}{|c|}{ Содержание элемента, мас. \% } \\
\cline { 2 - 3 } & в лигните & в золе лигнита \\
\hline $\mathrm{Ce}$ & $(3,6 \pm 0,4) \cdot 10^{-3}$ & $(66,8 \pm 6,7) \cdot 10^{-3}$ \\
\hline $\mathrm{Dy}$ & $(0,6 \pm 0,1) \cdot 10^{-3}$ & $(9,0 \pm 0,9) \cdot 10^{-3}$ \\
\hline $\mathrm{Er}$ & $(0,5 \pm 0,1) \cdot 10^{-3}$ & $(2,8 \pm 0,3) \cdot 10^{-3}$ \\
\hline $\mathrm{Eu}$ & $(0,9 \pm 0,1) \cdot 10^{-3}$ & $(11,3 \pm 1,1) \cdot 10^{-3}$ \\
\hline $\mathrm{Gd}$ & $(0,6 \pm 0,1) \cdot 10^{-3}$ & $(2,0 \pm 0,2) \cdot 10^{-3}$ \\
\hline $\mathrm{Ho}$ & $(0,1 \pm 0,03) \cdot 10^{-3}$ & $(21,2 \pm 2,1) \cdot 10^{-3}$ \\
\hline $\mathrm{La}$ & $(1,1 \pm 0,1) \cdot 10^{-3}$ & $(1,0 \pm 0,1) \cdot 10^{-3}$ \\
\hline $\mathrm{Lu}$ & $(0,05 \pm 0,02) \cdot 10^{-3}$ & $(43,7 \pm 4,4) \cdot 10^{-3}$ \\
\hline $\mathrm{Nd}$ & $(2,3 \pm 0,2) \cdot 10^{-3}$ & $(9,5 \pm 0,9) \cdot 10^{-3}$ \\
\hline $\mathrm{Pr}$ & $(0,5 \pm 0,1) \cdot 10^{-3}$ & $(15,2 \pm 1,5) \cdot 10^{-3}$ \\
\hline $\mathrm{Sc}$ & $(0,8 \pm 0,1) \cdot 10^{-3}$ & $(11,4 \pm 1,1) \cdot 10^{-3}$ \\
\hline $\mathrm{Sm}$ & $(0,6 \pm 0,1) \cdot 10^{-3}$ & $(2,0 \pm 0,2) \cdot 10^{-3}$ \\
\hline $\mathrm{Tb}$ & $(0,1 \pm 0,04) \cdot 10^{-3}$ & $(3,8 \pm 0,4) \cdot 10^{-3}$ \\
\hline $\mathrm{Tm}$ & $(0,2 \pm 0,04) \cdot 10^{-3}$ & $(27,6 \pm 2,8) \cdot 10^{-3}$ \\
\hline $\mathrm{Y}$ & $(1,5 \pm 0,2) \cdot 10^{-3}$ & $(8,0 \pm 0,8) \cdot 10^{-3}$ \\
\hline $\mathrm{Yb}$ & $(0,4 \pm 0,04) \cdot 10^{-3}$ & $253,7 \cdot 10^{-3}$ \\
\hline Сумма элементов & $13,85 \cdot 10^{-3}$ & \\
\hline
\end{tabular}


ности использования лигнитов бассейна среднего течения p. Енисей в качестве сырьевого источника для получения редкоземельных элементов.

Исследование выполнено при финансовой поддержке РФФИ и Правительства Красноярского края в рамках научных проектов № 16-43-240719 и 16-41-242156.

\section{Список литературы}

[1] Косынкин В.Д., Глебов В.А. Возрождение российского производства редкоземельных металлов - важнейшая задача отечественной экономики. Перспективные материалы, 2011, 2(11), 169-178. [Kosynkin V.D., Glebov V.A. The revival of the Russian production of rare earth metals - the high-priority problem of the national economy. Journal of advanced materials, 2011, 2(11), 169-178 (in Russian)]

[2] Козловский Е.А., Малютин Ю.С. Минерально-сырьевые ресурсы в экономике России. Маркшейдерия и недропользование, 2002, 3, 6-18. [Kozlovskiy E.A., Malyutin Yu.S. Mineral raw materials in the Russian economy. Marksheyderiya i nedropol'zovaniye, 2002, 3, 6-18]

[3] Новиков Н.И., Салихов В.А. Основные направления и перспективы развития минерально-сыревой базы цветных и редких металлов в мире и России. Вестник Томского государственного университета. Экономика, 2015, 2 (30), 138-150. [Novokov N.I., Salikov V.A. The main directions and prospects for the development of the mineral raw material base of nonferrous and rare metals in the world and in Russia. Vestnik Tomskiy state university, 2015, 2 (30), 138-150 (in Russian)]

[4] Салихов В.А. Экономическая оценка и комплексное использование попутных полезных компонентов углей и золо-шлаковых отходов углей (на примере Кемеровской области). НФИ КемГУ. Новосибирск: Наука, СО РАН, 2013. 224 с. [Salikov V.A. Economic evaluation and comprehensive utilization of associated mineral components of coals and coal ash and slag waste (in the Kemerovo region). NFI KemSU. Novosibirsk: Nauka, SB RAS, 2013. 224 p. (in Russian)]

[5] Озерский Ю.А., Еханин А.Г. Перспективы изучения и освоения ресурсов германия в нижнемеловых лигнитах Касской площади. Известия Томского политехнического универсиmema, 2009, 314 (1), 41-43. [Ozerskij Ju. A., Ehanin A. G. Prospects of studying and development of resources Germany in the Kasskaya Square lignites. Izvestija Tomskogo politehnicheskogo universiteta, 2009, 314 (1), 41-43. (in Russian)]

[6] Озерский А.Ю., Еханин А.Г. Ресурсы германия в нижнемеловых лигнитах каской площади и задачи по их изучению и освоению. Интерэкспо Гэо-Сибирь, 2006, 5, 48-53. [Ozerskij Ju. A., Ehanin A. G. Resources of Germany in the Kasskaya Square lignites and prospects of studying and development. Interexpo Geo-Siberia, 2006, 5, 48-53 (in Russian)]

[7] Макаров В. А., Подкопаев О. И., Козьмин Д. Г., Наидко В. И., Шиманский А. Ф., Копыткова С. А. Лигниты среднего течения р. Енисей и перспективы их использования для производства германия. Журнал Сибирского федерального университета. Серия: Техника и технологии, 2014, 7 (7), 862-871. [Makarov V. A., Podkopaev O. I., Koz’min D. G., Naidko V. I., Shimanskij A. F., Kopytkova S. A. Lignite from Central Watershed of the Yenisei River and Prospects for their use for Manufacture of Germanium. Zhurnal Sibirskogo federal'nogo universiteta. Serija: Tehnika i tehnologii, 2014, 7 (7), 862-871 (in Russian)] 
[8] Пашков Г.Л., Сайкова С.В., Кузьмин В.И., Пантелеева М.В., Кокорина А.Н., Линок Е.В. Золы природных углей - нетрадиционный сырьевой источник редких элементов. Журнал Сибирского федерального университета. Серия: Техника и технологии, 2012, 5 (5), 520-530. [Pashkov G. L., Saikova S. V., Kuzmin V. I., Panteleeva M. V., Kokorina A. N., Linok E. V. Natural coal ash - unconventional source of rare elements. Zhurnal Sibirskogo federal'nogo universiteta. Serija: Tehnika i tehnologii, 2012, 5 (5),520-530 (in Russian)] 